\title{
Assessing Grievances Redressing Mechanism in India
}

\author{
Subhash Chander \\ Govt. P.G. College \\ Sector - 14, Karnal \\ Haryana (India)
}

\author{
Ashwani Kush \\ University College \\ Kurukshetra University,Kurukshetra
}

\begin{abstract}
Various online services for the benefits of citizens are being provided by various states in India. Major aim of providing such services online is to empower the citizens. Major implementations regarding services for citizens in India include various acts for rights of human beings in democratic states. The major problem of today's countries is corruption, bureaucracy and both are related with each other. There are so many grievances to all people residing in democratic countries like India. In Indian democratic structure Department of Administrative Reforms and Public Grievances (DARPG) is responsible for tackling the problems of grievances of various departments of different states and centre. In this paper four states and their grievance redressing system is taken into consideration. Various metrics related with the grievance portals have been considered and scale has been devised. The performance of all these four Indian states in grievance redress process has been measured on the scale. On the scale certain numerical values have been assigned for ten services as per their relevance for the citizens. Based on these values certain results have been shown in the graphical form. Various portals taken into account are HarSamadhan of Haryana, eSamadhan of Himachal Pradesh, SWAGAT of Gujarat and JanMitra of Karnatka
\end{abstract}

\section{Keywords}

Public grievance redress, CSC, ICT, Metrics, E-governance

\section{INTRODUCTION}

A large number of government websites have been set up in India over the last few years to deliver a wide variety of information and services to its citizens. The concepts of quality and security for a website need to be quantified in some way to avoid subjective interpretations [14].There are many areas where Information and Communication Technology (ICT) has been applied for the benefits of citizens. It may be field of reservation of tickets, payment of bills online or withdrawal of amount from ATM. Increasingly land registration, education, health care, and voting are being conducted electronically using ICT. People around the Globe from few years from now will be carrying a handheld computer connected to the Web to get the information about the World at their fingertips [22]. But there are still many areas where common man feels helpless in case his work is denied or not being done by the officials in the present governance process. One can imagine the situation when all required documents are complete with you and you are denied service from one reason or the other. This grievance mechanism system is necessary in each and every democratic state. It is the very important to have such mechanisms because one person can not have full knowledge of every department and its working. Due to lack of this knowledge persons employed there or working there try to apply various delaying techniques and person has to visit many times unnecessarily to the offices for long time. Certain employees in offices may be lethargic or may be persuading corruption in the name of facilitation fees. In such circumstance one may not have the knowledge about the hierarchical system available in various offices. One may not know whom to meet or complain if he is being ignored by the staff of particular organization. One may not have knowledge of higher authorities in the current process that can help in solving his problem. But Availability of grievance redress mechanism in the countries as well as in states may help lot in removing many difficulties of the common man. Availability of such mechanisms will ensure transparency in the working of various government departments. The rest of the paper is organized here as follows. Section 2 represents grievance redress mechanism systems in four states, section 3 defines certain metrics for the evaluation of such mechanisms, section 4 shows experimental survey and analysis, section 5 provides conclusion of the paper.

\section{GRIEVANCE REDRESS MECHANISM IN DIFFERENT STATES}

New web technologies have the potential to fulfill the aims of e-government. These technologies have the potential to increase transparency, promote citizen understanding of their government, and allow them to participate in the political process in new ways But governments are not very much serious about it. Only $20(11 \%)$ of the 178 member UN states with Government websites provided any mechanism for citizen feedback. In 2008, only 11 percent of the 92 countries committed to utilizing citizen input gathered via egovernment websites for use in the decision making process [20]. In the emerging electronic environment, Internet plays an increasingly important role in the delivery of information, conducting business and business transactions. The main link between the enterprise supplying information and the recipient of information and services is the website. The strength of the link is essential for the distribution of information and services. Thus, the quality and security of website are of paramount importance [14].In India many acts and rules related with citizens' convenience have been implemented. Some others may be in the pipeline in this direction. To name a few Right to Information (RTI) act 2005, Right to Education (RTE) act 2010 and Right to service (RTS) act 2011 are being implemented by keeping in mind the convenience and services for native citizens. Citizen Charter may also be one of the necessary steps in successfully implementation of such acts. Through citizen charter one may have information about the minimum \& maximum time for the particular service. Through RTI act one has the right to know about the particular information which is not generally shown or visible to the users. Certain time frame has been set in this regard and after that time frame one may approach to higher authorities for necessary action and erring officials of the particular department may be fined and even jailed. In India, the number of queries related with the RTI has increased tremendously and many governments have provided this facility online and even through ubiquitous devices to its 
citizens so that they file their queries sitting at their homes or nearby internet Cafes.

\subsection{Public grievance system at Centre level}

In India DARPG is major department for handling grievance of citizens and its related problems. In the early stages this job was started department wise but some departments could not make much progress in this field. Hence Government started an online web enabled portal - Centralized Public Grievance Redress and Monitoring System (CPGRAMS) in 2007, which helps in streamlining of the registration, transmission, tracking and monitoring of grievances both at the citizen and departmental level [1]. Various features of CPGRAMS [5] include $24 \times 7$ facility for citizens to post grievance and grievance of more than 20 departments can easily be posted and handled from one stop portal. Task of various departments, organizations, governments has been simplified in the manner that they can do effective monitoring for pending grievances. It facilitates the generation of automated letters like acknowledgement and final reply letters etc. It can handle grievances and complaints received manually in the concerned office, department or organization by entering them, forwarding them to the concerned may be subordinate organizations, departments or offices. It can help in checking the status of the various grievances by users and departments. Various officials have been trained for handling grievances online and departments having more public dealing have been taken into consideration. The system has two interface one for the citizens and other for the concerned departments. One can send his query or grievance directly to the concerned Ministry/Department and get an immediate acknowledgement, can expect a reply from the department in two months. But two month tome is more and must be reduced to bring transparency and confidence of people in the present system. Various useful reports can also be generated from this system and communicate with the complainant. It is very convenient system for citizens and they also have facility to issue reminders to redress grievances speedily. Centre government has received 27,272 public grievances in the year 2011from different states [16]. Out of these 4,976 were received from Tamil Nadu state and 1084 from Haryana. Various common features of this grievance portal are here as follows.

(1) It is easy to use and operate for users and departments.

(2) It is online system based on web technology and grievances can be lodged from anywhere on $24 \times 7$ basis.

(3) Users get acknowledgement and time to be taken for redressing the grievance.

(4) Grievance can be forwarded at the same time to many departments and related sub departments online within seconds and there is control on red tapism.

(5) Departments can load grievance online if any citizen files a written (offline) grievance to any department.

(6) Local language (Hindi) i.e. National Language facility is here to use the portal.

(7) Various useful reports can be generated from this system.

(8) Networking of all the public grievance officers on a single platform which facilitates better monitoring at highest level [7].
(9) Grievance related documents can be attached after scan and these scanned documents can also be seen at all levels wherever the grievance is transferred.

\subsubsection{Haryana}

It is mission of every government whether state or centre to make governance effective, transparent and provide online solutions and feedback, reduce delivery costs. The increased level of education, income and awareness has given birth to more and more aspirations and expectations of people. To meet expectations of citizens many states in India have implemented online grievance redress online Systems. Haryana is the first State in the country to launch a Web Portal based Centralized Public Grievances Redress And Monitoring System known as 'Harsamadhan'[3] to provide a quick grievance redress mechanism to empower the citizens [4]. CPGRAMS has been implemented in Haryana on pilot basis in june 2010 in association with State Government and National Informatics Centre (NIC) state centre, Haryana. 'Harsamadhan', is a Centralized Public Grievances Redress and Monitoring System and named appropriately with meaning 'solution for grievances of everyone' and solutions of grievances in Haryana.It is an online, paperless and timesaving process to handle grievances. The user friendly new portal will help people getting their grievances redressed quickly and satisfactorily. It would prove a significant step in the field of e-governance in the state and provide solutions of the problems and inconveniences of the common man [6]. But by looking at the number of cases the website has received until recently - and indeed the number of cases resolved as yet - the whole thing seems not to be good at all. Portal has received no more than 288 complaints since its launch in 2010 , out of which 269 cases remain pending with several departments [8]. These figures show that neither the citizenry nor the bureaucracy might be ready to accept the new shift towards technology and governance. As per NIC officials only 16 cases registered on harsamadhan.gov.in have been solved and disposed of as yet, Out of a total of 288 cases, 269 haven't been solved. Sixteen cases have been solved and three needed no action [8]. But this does not mean there is fault in the system. Reasons may be lack of interest in the stakeholders, training work, advertisement regarding the facility available to rural population. There is need to reduce the time for solving a grievance whichever it may be. In case of birth certificate grievance Haryana portal is taking one month time to resolve. Moreover users may be motivated to use such online portals but it is also responsibility of the departments to redress grievance in a speedy manner so that more and more people may be enthusiastic to use such portals. Concerned officials not cooperating in the online redressing process must be punished by any of the ways may be transfer, increment stoppage, or any other means. Certain benefits of grievance portal are here as follows.

(1)Such portals are useful and easy to use for citizens, governments and various departments.

(2)It can handle grievances of various departments.

(3)One can track the status of his grievance online.

(4)Language choice facility is available for the citizens. 
(5)Users are satisfied when they get acknowledgement regarding status of their grievance from the portal.

(6) It is transparent system and officers at various levels can check action taken against a particular grievance [5]. Snapshot of the portal is shown here in fig. 1 .
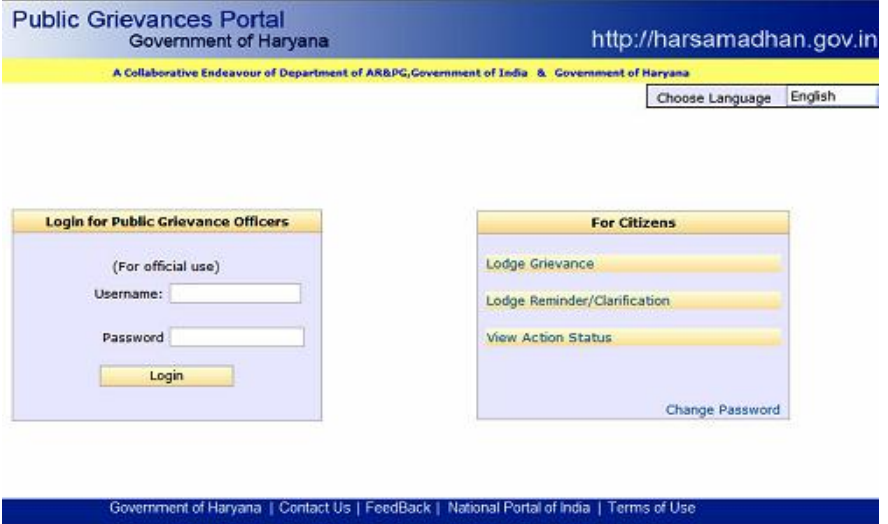

Fig 1: Snapshot of grievance portal, Source [7]

\subsubsection{Himachal Pradesh}

Himachal Pradesh is a state which came into existence on $25^{\text {th }}$ January 1971 and so many projects in e-governance have been implemented by State Government and NIC. In case of Common Service Centre (CSC) named as Lok Mitra Kendra, Out of 3366 CSC to be established in the state, 2576 have been rolled out as on January 2011 [10]. SUGAM centres provide all citizen services and information at one place, cutting across different tiers of administration, providing services at the doorstep of rural community. Services provided on these SUGAM centres include like Voter Registration and Issuance of Voter Id, Land record (Nakal/ Jamabandi), Revenue (HimBhoomi-Land records forms), Transport (Vahan - Vehicle registration and Saarthi - Driving license), Bus booking \& Time table, Caste certificates, Vacancy listings, Electricity and telephone bills, Tourist Information etc [12]. SMS facility is also being used by these centres for sending status of the service to the citizens, when the information/ service is ready for delivery or there is some deficiency in the documents submitted by the citizen to avail a service. For promoting IT skills in colleges computer labs have been provided to students at degree and post graduate level in various Government colleges of Himachal Pradesh. eMarg Darshan [10] project attempts to provide information about various welfare schemes provided to citizens by state Government. E-iph (e-Irrigation and Public Health), Irrigation and Public Health Department has implemented a project called e-iph which automates its functions by various other systems like e-Sameeksha, e-Sanchalan, e-Samadhan and eService. e-Sameeksha is a Control Management Process that helps in monitoring of works. E-Sanchalan helps in execution of works by automation of day-to day business process. ESamadhan has been implemented in the system to handle the public grievances of the state in December 2008 [18]. EService is a personnel Management Information System (MIS) system for keeping a record of the employees working within the department. All these systems constitute the e-iph system. E-Samadhan is the Grievance Redressal System portal of the Government of Himachal Pradesh. It is web-based software for speedy redress of grievances that has been developed by NIC, Himachal Pradesh using ASP.NET. It gives an instant view of the grievance to both, the concerned office and the public. It also shows the department-wise pending summary of the grievances. This project has enhanced transparency and accountability and reduced paper work and corruption [10]. Each grievance registered on the portal would get a unique identity number and would help the user in tracing the status of the grievance later on by the user. Snap shot of home page of the Portal e-Samadhan and Inaugural session of the portal is shown in Figure 2 and 3 below.

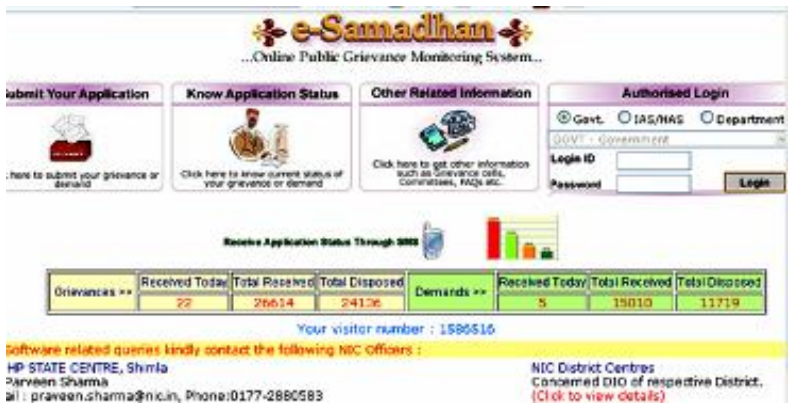

Fig 2: Snapshot of portal eSamadhan

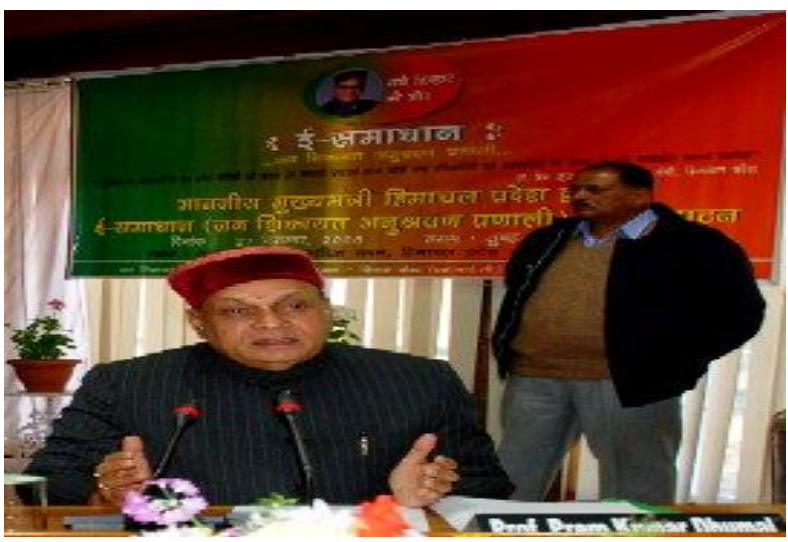

Fig 3: Inaugural session of the portal eSamadhan

Various benefits or features [12] of the portal are here as below.

(1) Transparent and accuracy in the system.

(2) Grievances are classified at the same time.

(3) Grievances are disposed in faster way as compared to traditional way.

(4) Maximum time limit of resolving the grievances is specified with each grievance submitted.

(5) SMS facility helps to know the status of the grievance and helps the more users in motivating for use such services online.

(6) Corruption can be reduced as compared to traditional way of Grievance redress, where no time limit for solving a grievance is specified and also one can not know the status of his grievance in the manual process of handling such grievances.

(7) Anytime and anywhere basis service for citizens. Citizens can lodge the grievance while sitting at their homes, Internet 
cafes or from counters of SUGAM centres available at district, taluka and CSCs at village levels.

(8) For solving grievance online many employees or departments may require coordination among themselves.

(9) It is economical way for the users and departments points of views.

(10) In case, maximum time of resolving the grievance is exhausted then accountability of the concerned official may be fixed easily, which was a typical job otherwise in case of manual systems.

(11) Implementation of such systems assures optimal use of time for users and employees of departments.

(12) Biasness is reduced in case of use of such portals.

(13) Helps in speedy disposal of public grievances in a time bound manner.

(14) Other advantages of e-Samadhan include low cost, Transparency, Instant availability of information regarding the grievance \& action taken, Effective monitoring, timely disposal of grievance, accountability of officials and concerned officers, reduction in the paper work [2] .

(15) The "e-Samadhan" application is safe for 12 OWASP vulnerabilities. For login authorization MD5 (Message-Digest algorithm 5) has been used as cryptographic hash function with a 128-bit hash value [9]

\subsubsection{Gujarat}

Gujarat is the state which is rich from both states not only in size and facilities but also in implementation of eGovernance. The state comes under aspiring leaders' category which is among top leaders among various states in eGovernance. Government has interaction with its people through various means. Some of the means are Yojana, forms and schemes. Grievance redress and monitoring of complaints related to delivery of services is another type of $\mathrm{C} 2 \mathrm{G}$ Citizen Government transaction [11]. Some of the successful eGovernance projects initiatives taken by Gujarat are in the area of Land record computerization, Gujarat Geographic information system, Gujarat State wide area network and State-Wide Attention on public Grievance by Application of Technology (SWAGAT)[13]. The SWAGAT system comprises of an online public portal and video-conferencing setup that connects the Chief Minister to all the district and sub-district level officers, as well as the complainant in real time. SWAGAT has an integrated grievance tracking module that tracks the progress of each complaint from the time it is filed. It is a three-tier grievance redress system in Gujarat: Taluka, District and State level. All grievances are reviewed by the Chief Minister himself. Here grievances are handled at various levels by officers and grievance is passed automatically at higher level officers if it not solved for a specific period at this stage by the current grievance officers. This hierarchy goes up to Chief Minister Office level. The grievance which is not sorted at all these mid between levels goes to Chief Minister and Chief Minister himself conducts a hearing via videoconference on the 4th Thursday of every month. All Taluka and District-level officers and all secretaries join the hearing online, along with complainants whose grievances are yet to be resolved. The following figure 4 and 5 completely explains the working of the SWAGAT and homepage of the Gujarat portal respectively.

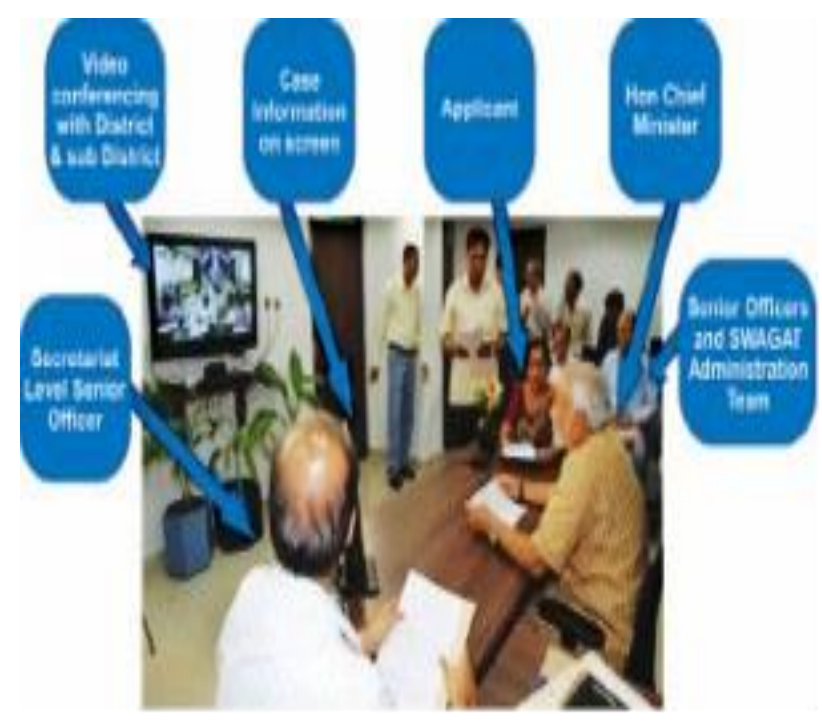

Fig 4: working of the SWAGAT in Gujarat, Source[13]

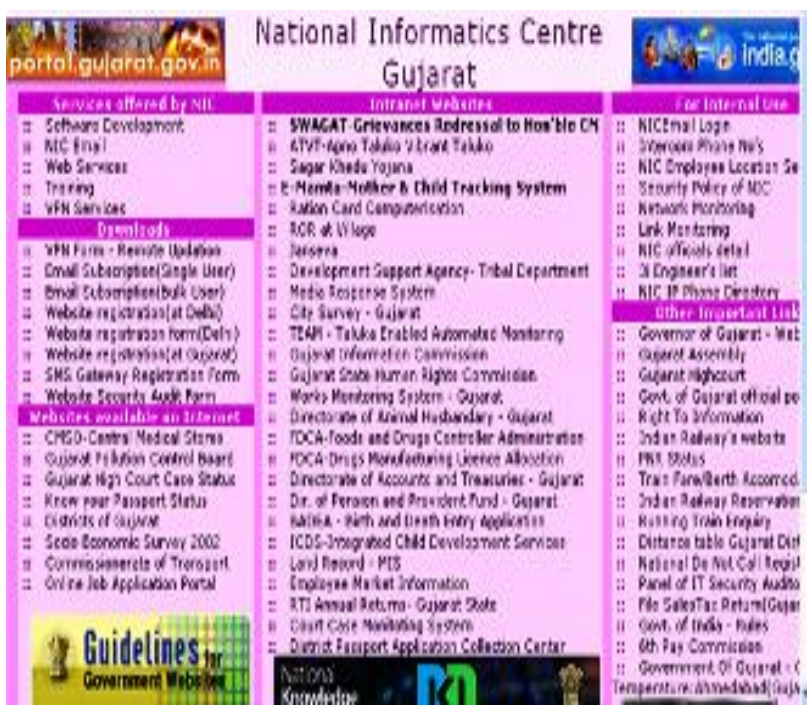

\section{Fig 5 Gujarat portal Homepage}

The CM's official Website [15] is the central hub of all things related to him. This website is a comprehensive repository of information on his activities, plans and views. The portal is available in five languages - Hindi, English, Gujarati, Marathi and Sanskrit. Disposal rate of grievances of this portal is $92.45 \%$ [13].This project has earned so many rewards at National and International Levels. With the rollout of Gram SWAGAT, in February 2011, the system has now reached villages and will help villagers to file or lodge their grievances sitting at their homes. Working of SWAGAT is shown in figure 6 below.

\subsubsection{Karnatka}

Karnataka has been ranked as leader in e-Readiness in the country by Department of Information Technology (DIT) Government of India (GOI). The state has implemented several e-Governance projects like Bhoomi and Nemmadi which can be replicated in other states. All procurements are made online to enhance transparency in the system. KSWAN 
project being implemented for connecting various departments and their services [19]. Bangalore One (B1) aims to provide integrated services to the citizens using Information and Communication Technology (ICT) to enhance speed, convenience and certainty in providing citizen services. Major aim of the B1 is to provide citizens all G2C and G2B one stop services in efficient, reliable, transparent and integrated manner on self sustained basis and through multiple delivery channels (Kiosks, mobiles and Internet) [17]

\section{Systematic SWAGAT State SWAGAT every $4^{\text {th }}$ Thursday of the Month \\ 9:00-12:00 grievance applications registered online at SWAGAT Office: details immediately available to concerned Officers \\ 12:00-15:00 Officers enter responses and information online \\ 15:00 Hon CM \& Senior Officers interact with applicants. District and Sub-District Officers attend the program through video-conferencing \\ Cases are redressed on the same day or in time-bound manner. All directions given by Hon $\mathrm{CM}$ are formally recorded on the same day}

\section{Fig. 6 Working of SWAGAT [15]}

Janmitra is a public grievance redress system which provides multiple channels for a citizen to file grievances or provide feedback through the helpline (by a phone call) or through a website or through their mobiles, or through post [21]. Snapshot of Janmitra portal is shown in figure 7 below. Fig 8 shows the Homepage of the Haryana portal in Hindi.

\section{జనేషిత్,}

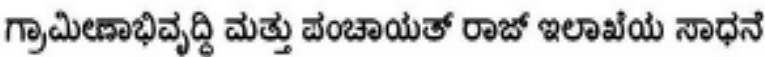

\section{Welcome to Janmitra}

\section{Please click on your District Name}

\section{బ่อก่ร่อठี \\ m. \\ Bangalore Rural}

Fig. 7 JanMitra Portal of Karnatka

\section{METRICS FOR ASSESSMENT OF PORTALS}

Since the portals are related with the grievance redress mechanism special metrics need to be taken care of. There are number of metrics to assess performance of web portals but here one will have to take only metrics related with the performance of grievance redress portals. Scale taken into consideration is $1-10$.
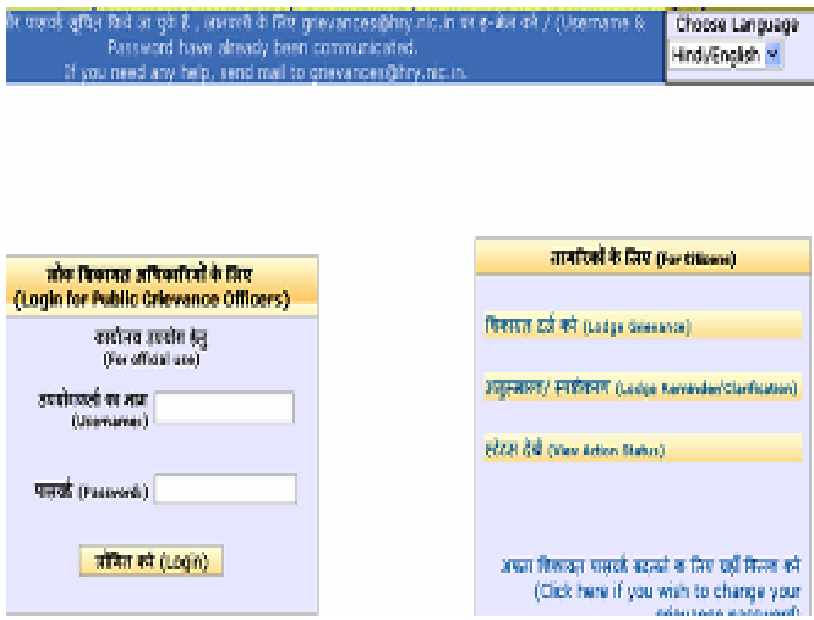

Fig. 8 HarSamadhan in Hindi

If a portal is having the facility it is awarded 7-9 and if facility is not available then on scale 1-3 are given. Ultimately by adding the scores of each of the portal maximum weighted portal are reckoned as best out of all these. Performance of all other portals is also based on the total of their weights as per their performance. Metrics considered for these portals are shown here in a table 1.

\section{EXPERIMENTAL SURVEY AND ANALYSIS}

The Four above mentioned portals have been tested on the certain metrics mentioned in table 1 . On the basis of that analysis certain scores have been given to each of the portals on the basis availability or popularity of particular metric.

Table 1 Showing metrics used for portals assessment

\begin{tabular}{|l|l|l|l|l|}
\hline Site map & FAQ & $\begin{array}{l}\text { News and } \\
\text { events }\end{array}$ & $\begin{array}{l}\text { Grievance } \\
\text { status } \\
\text { knowing } \\
\text { facility }\end{array}$ & $\begin{array}{l}\text { Info } \\
\text { richness \& } \\
\text { popularity }\end{array}$ \\
\hline $\begin{array}{l}\text { No. of visitors } \\
\text { and } \\
\text { convenience }\end{array}$ & $\begin{array}{l}\text { Services } \\
\text { \& other } \\
\text { informati } \\
\text { on }\end{array}$ & $\begin{array}{l}\text { Performa } \\
\text { nce \& } \\
\text { efficiency }\end{array}$ & Impact & $\begin{array}{l}\text { Grievance } \\
\text { redressed } \\
\text { rate }\end{array}$ \\
\hline
\end{tabular}

(1)Sitemap: Official portal of Haryana for grievance redress is Harsamadhan. This portal gives mainly two Columns namely login for public grievance officers and citizens. Snapshot of the portal in Hindi version (shown in figure 9) shows the unavailability of the sitemap option which is helpful feature for knowing what information can be available from the portal. ESamadhan portal of Himachal Pradesh is also lacking on this feature of sitemap. But it has more information and facilities as compared to Harsamadhan. On SWAGAT portal other important information on the 
columns namely governance, media, interact, e-books, citizen journalism, downloads, gallery and you said it is available, also various comments by citizens are also available on the portal which motivate the other users to avail the facility to redress their grievances. Complete working of the grievance redress mechanism is available on the portal. But Sitemap option is also not available on this portal. Janmitra is portal used by Karnataka government to tackle issues of grievances. This portal is divided into three parts namely Bangalore rural, Dharwad and Kolar. English and Kanadda are the language options provided for entering grievances on the portal. Grievances or complaints may be lodged through various methods namely, telephone, web, mobile phone and postal. Number of grievance received through various modes is also available on the portal. The number of total visitors of the sites is also shown on the portal. Sitemap option is also not available on the portal. Hence each of these portals is assigned weights 1 to 3 .

(2) FAQ: It is an important option and must be available at every portal to go further for getting information from the portal. It must have questions that what information or functions can be performed with the help of the portal. FAQ must include the questions about maximum time to redress a grievance of a particular department and that will increase the transparency in the system and would increase the utilization of the portal by users. FAQ facility is available on the eSamadhan portal of Himachal Pradesh whereas other state portal lack on this feature. Hence eSamadhan is given the weight age 9 and others are awarded from 1 to 3 .

(3) News and events: Portals related with grievance redress must flash certain news related with the use of the portal or its grievance mechanism so that more and more people may start using it. Particular information, like on SWAGAT the particular day for handling grievance, related cases may be flashed to the users so that they may utilize the facility. But such feature is not available at any of these grievance redress portals. Each of the portals is assigned 1 to 3 weights.

(4) Grievance status knowing facility: Once grievances/complaints are lodged by citizens they must be able to know the status of their grievances or complaints. They must be able to know the action officials have taken in this regard. Haryana and Himachal portals have this facility for getting information about the action taken by the officials about the particular grievance on the basis of the grievance registration number which is obtained at the time of the lodging the grievance. Whereas in the case of Gujarat, citizens can directly see the working of the complete redress process in the presence of the concerned officials and Hon'ble Chief Minister. In case of JanMitra citizens are provided status updates and alerts by the portal. After completion of a particular grievance case concerned citizens are informed accordingly about the result of the grievance. Hence on the scale SWAGAT is on 8, Janmitra, Harsamadhan and eSamadhan are on 7 each.

(5) Information richness and popularity:

Citizens portals must have facility to get related information on each of the portals one may require. ESamadhan portal has more information as compared to other grievance redress portals. It has information related to the NIC officials of all districts of Himachal Pradesh. Other related information column is having more information that can be utilized by the citizens. Himachal portal is having more information like daily account of grievances received and redressed, SMS facility to know status of your application submitted, language options, other related information column showing FAQs, grievance committees and cells, for software related queries one is having email address and contact number of the concerned official direct on the home page of the portal, whereas Haryana is lacking on all such parts In Harsamadhan Portal only links to State and national Portal are given. In case of SWAGAT there is more information and is much popular in the citizens of Gujarat. Janmitra has less information as compared to other grievance redress portals. On the scale Himachal Pradesh portal is on 9, Gujarat on 8, Haryana on 7 and Karnataka at 3.

(6) Number of Visitors \& convenience: The number of visitors on a portal shows its usability and easiness for the users while utilizing the portal. The number of users on the HarSamadhan and eSamadhan are 80646 and 1586516 respectively. HarSamadhan was launched in June 2010 whereas eSamadhan was launched in December 2008. On average basis Himachal portal has received 39662.9 grievances whereas Haryana portal has receive only 3360.25 grievances on monthly basis, which is very less as compared to Himachal grievance redress portal. SWAGAT started in year 2003 and has redressed $93.45 \%$ of the total grievances received. JanMitra has only 4695 visitors which is very less in number as compared to other portals. The number of grievance lodged through various channels is as follows and shown in table 2 .

Table 2. Grievances at Janmitra portal

\begin{tabular}{|l|l|}
\hline Number of citizens registered & 154 \\
\hline Number of phone call complaints & 118 \\
\hline Number of complaints filed on Web & 60 \\
\hline Number of complaints from Mobiles & 32 \\
\hline Number of postal complaints & 17 \\
\hline Number of janaspandana complaints & 01 \\
\hline Total & 228 \\
\hline
\end{tabular}

Number of visitors determines that over all on the scale Himachal portal is on 9, Gujarat is on 8 whereas Karnatka is on 7 and Haryana is on 3 as the number of grievances redressed by Haryana is very less.

\section{(7) Services and other citizen related}

information: The number of services and other related information on grievance portals is an important issue. On 
Haryana grievance portal there is lack of information and other services. The only information available here is lodge grievance, status of grievance and view action status. Moreover the Himachal portal of grievance is having more information like number of grievances and demands received and disposed off. Also applicants can know status of their application through SMS which is most commonly used feature of mobile phones in India. Also Mobile penetration is increasing day by day in India which will help in popularizing such features and grievance portal itself. Recent World Bank study shows that a $10 \%$ increase in mobile phone subscribers is associated with a $0.8 \%$ increase in economic growth while $10 \%$ increase in high speed internet connections is related with a $1.3 \%$ increase in economic growth [22].Citizens facing difficulties in utilizing the available features and facilities may also talk telephonically or email the concerned officials. Information regarding various District Informatics Officers (DIOs) is also available on the portal. The statistics about the number of grievances and demands received and disposed off are available on the portal in table 3 .

In Janmitra status of the complaint or grievance is communicated back to the complainant - the communication loop becomes complete. Grievance is tracked till its completion. Here complaints are indexed and assigned to authorities from respective departments who will interact with the complainant directly over phone/email or in person, as the case may be, to take it to closure. Although information is not more yet there is a lot of overlapping of information on the portal. SWAGAT portal is having more information including latest news, e-books and other political news. It has also links with the face book and twitter. On the scale Himachal is on 9 and Gujarat is on 8 point scale whereas Haryana and Karnataka are on 3 and 7 respectively.

Table 3. Grievances at Himachal portal

\begin{tabular}{|c|c|}
\hline \multicolumn{2}{|l|}{ Grievances } \\
\hline Received Today & 22 \\
\hline Total Received & 26614 \\
\hline Total Disposed & 24136 \\
\hline \multicolumn{2}{|l|}{ Demands } \\
\hline Received Today & 5 \\
\hline Total Received & 15010 \\
\hline Total Disposed & 11719 \\
\hline
\end{tabular}

(8) Performance \& efficiency: Performance depends on the time taken in redressing of the grievances of various departments. If there is case of birth certificate related grievance then it may take maximum time as one month or 14 days. It has been verified on the two of these grievance portal one portal of Himachal Pradesh is having 14 days time to redress the same grievance Haryana is taking one month.
Moreover the grievance is not redressed till last three months at Haryana portal. On the whole portal should have minimum time to redress the grievances and that will increase the confidence of the citizens in utilizing the portal. Performance wise Himachal portal is much better as compared to Haryana portal. In case of Gujarat SWAGAT portal on the Hon'ble Chief Minister website is redressing grievances on the $4^{\text {th }}$ thrusday of every Month. Only limited grievances reach up to that level because most of the grievances are redressed by the officials at their levels that are in their purview or right. Various types of fonts facilities is available on the portal. Also Gujarat portal is performing well and that is the reason that redressing rate of grievances on this portal is more than $90 \%$. On Janmitra grievances or complaints can be lodged on the basis of Karnataka Service Guarantee Act (KGSA). On the scale Himachal is on 9, with Gujarat on 8 and Karnatka on 7 and Haryana on 3.

(9) Impact: Impact on the citizens can be known through the number of visitors and information available on the portal. More and more people will be using the portal if their grievances are redressed within a short span of time. There is also need of providing grievance redressing facilities for those departments which are mainly attached or related with public dealing and rural population. Janmitra provides the facility for rural people and SWAGAT program in Gujarat has been extended up to village level in the name of GRAM SWAGAT as on 1st February 2011. SWAGAT Online program has helped the rural people living even in remotest corner of the state in getting their problems solved quickly. On the scale Himachal portal is on 8 , Karnatka and Gujarat on 7 and Haryana on 3.

(10) Grievances redressed rate: On Himachal portal eSamadhan total grievances received are 26614 and grievances redressed are 24136, whereas demands received are 15010 and total demands disposed of are 11719 which comes out to be $90.69 \%$ and 78.07 respectively. Disposal rate of grievances of the SWAGAT portal is $92.45 \%$. On Haryana Portal position is very bad and $93.4 \%$ of the grievances are in pending state. As per source [8] out of 288 complaints registered 269 cases still remain pending with several departments. Whereas Centre CPGRAMS has received $1,72,487$ complaints in 2011 , and out of these1,47,028 have been disposed of and this comes out to be $85.24 \%$. In case of Janmitra one is not able to find the status and hence has been awarded 2 on the scale. Whereas SWAGAT has been awarded 9, eSamadhan 8 and Harsamadhan 1 point on the designated scale.

\section{CONCLUSION}

Effective and timely redressing of public grievances is an important question in democratic state like India. In democratic countries redressing of public grievances is main characteristic of responsive and responsible governments. Now a lot of progress has been made by many states in the era of e-Governance and new and new services are being provided online to the citizens of the state. Old methods of governance will have to be swapped to give way to new and 
innovative methods of governance. Table 4 is showing the overall weight age of each of the portal.

Table 3. Assessment of Grievance portals

\begin{tabular}{|l|c|c|c|c|}
\hline Metrics & $\begin{array}{l}\text { Harsamad } \\
\text { han }\end{array}$ & $\begin{array}{l}\text { eSam } \\
\text { adha } \\
\text { n }\end{array}$ & $\begin{array}{l}\text { SWA } \\
\text { GAT }\end{array}$ & $\begin{array}{l}\text { Janmi } \\
\text { tra }\end{array}$ \\
\hline Site map & 1 & 3 & 2 & 1 \\
\hline FAQ & 1 & 3 & 2 & 1 \\
\hline News and events & 7 & 7 & 8 & 7 \\
\hline $\begin{array}{l}\text { Grievance status knowing } \\
\text { facility }\end{array}$ & 7 & 9 & 8 & 3 \\
\hline Info richness \& popularity & 7 & 9 & 8 & 3 \\
\hline $\begin{array}{l}\text { No. of visitors and } \\
\text { convenience }\end{array}$ & 3 & 9 & 8 & 7 \\
\hline $\begin{array}{l}\text { Services \& other } \\
\text { information }\end{array}$ & 3 & 8 & 7 & 7 \\
\hline Performance \& efficiency & 3 & 8 & 9 & 2 \\
\hline Impact & 1 & 74 & 62 & 41 \\
\hline Grievance redress rate & 34 & 8 & 7 \\
\hline Total Weights & & 9 & & 3 \\
\hline On the basi of the above & & & & \\
\hline
\end{tabular}

On the basis of the above table it can be easily claimed that eSamadhan portal of Himachal Pradesh is best out of all the four grievance redress portals. Then SWAGAT portal has received 62 points on the scale and is much better than the grievance portals of Haryana and Karnataka states. Before rolling out and replication of such projects requires a rigorous thinking regarding what the user requires. Why users are not availing a particular system and there is need to remove those intricacies involved in the processes for utilizing such portals. News and events columns must be available to such portals. Also diagrammatic representation of assessment summary is shown in figure 9 below.

\section{Assessment sum mary of grievance portals}

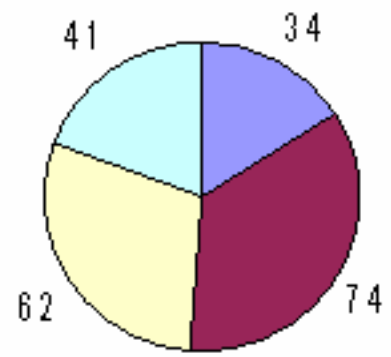

Harsamadhan

e $S a m a d h a n$

$\square$ S 'W' AGAT

$\square$ Janm itra

\section{REFERENCES}

[1] "Extension of CPGRAMS to states ", A discussion paper, available at www.darpg.nic.in

[2] Available at www.csinihilentegovernanceawards.org

[3] Available at www.harsamadhan.gov.in

[4] Available at www.punjabnewsline.com

[5] Available at www.darpg.nic.in

[6] Available at www.governancenow.com

[7] "Centralized Public Grievances Redress And Monitoring System for Haryana (HARSAMADHAN)“,User Manual, published by nic hsu, Chandigarh

[8] Available at www.timesofindia.com, March 19, 2012

[9] Sen Bhim \& Bahadur Rajesh," e-samadhan grievance monitoring system" , Ch 13, available at csinihilentegovernanceawrds.org

[10] Available at www.hp.gov.in

[11] Jayanti R.," Mahitishakti-the citizen service portal", Volume 1,Number 5,An e-governance bulletin from Gujarat Informatics Limited (GIL), 2003

[12] Available at www.egovreach.in

[13] Available at www.egov.eletsonline.com

[14] Sarnot S.L., Nandwani U.K. and Sondhi R.P.," Website Quality - A Prerequisite to Addressing Citizen Expectations in e-Governance", ICEGOV2008, December 1-4, 2008, Cairo, Egypt, ACM 978-1-60558$386-0 / 08 / 12$

[15] Available at www.narendramodi.in

[16] Available at www.zeenews.india.com on $28^{\text {th }}$ march, 2012

[17] Chakravarti Bhudeb, Venugopal M.," Citizen Centric Service Delivery through e-Governance Portal - Present Scenario in India", A White Paper published by National Institute for Smart Government (NISG)Hyderabad (2008)

[18] Available at www.hillpost.in

[19] Cutomer centric e-Government , state consultation workshop in partnership with NaasCom, Banglore report by DIT,GOI, $5^{\text {th }}$ November 2011 and available at www.negp.gov.in

[20] Walker Shawn T., "Budget Mapping: Increasing Citizen Understanding of Government via Interactive Design", Pp 1-9, Proceedings of the 43rd Hawaii International Conference on System Sciences, IEEE computer society 2010

[21] Chandra Deka Ganesh and Malaya Dutta Borah ," ICT Its Role in e-Governance and Rural Development", ACC 2011, Part II, CCIS 191, pp. 210-222, SpringerVerlag Berlin Heidelberg 2011

Fig. 9 Assessment summary of grievance portals 